\title{
Changes in the ruminal fermentation and bacterial community structure by a sudden change to a high-concentrate diet in Korean domestic ruminants
}

\author{
Mingyung Lee', Sinyong Jeong', Jakyeom Seo ${ }^{1,2}$, and Seongwon Seo ${ }^{1, *}$
}

\author{
* Corresponding Author: Seongwon Seo \\ Tel: +82-42-821-5787, Fax: +82-42-823-2766, \\ E-mail: swseo@cnu.kr \\ ${ }^{1}$ Division of Animal and Dairy Sciences, Chungnam \\ National University, Daejeon 34134, Korea \\ 2 Department of Animal Science, Pusan National \\ University, Miryang 50463, Korea \\ ORCID \\ Mingyung Lee \\ https://orcid.org/0000-0001-8952-9725 \\ Sinyong Jeong \\ https://orcid.org/0000-0002-0790-7727 \\ Jakyeom Seo \\ https://orcid.org/0000-0002-9176-5206 \\ Seongwon Seo \\ https://orcid.org/0000-0002-4131-0545
}

Submitted Apr 3, 2018; Revised May 7, 2018; Accepted Jun 4, 2018
Objective: To investigate changes in rumen fermentation characteristics and bacterial community by a sudden change to a high concentrate diet $(\mathrm{HC})$ in Korean domestic ruminants. Methods: Major Korean domestic ruminants (each of four Hanwoo cows; $545.5 \pm 33.6 \mathrm{~kg}$, Holstein cows; $516.3 \pm 42.7 \mathrm{~kg}$, and Korean native goats; $19.1 \pm 1.4 \mathrm{~kg}$ ) were used in this experiment. They were housed individually and were fed ad libitum with a same TMR (800 g/kg timothy hay and $200 \mathrm{~g} / \mathrm{kg}$ concentrate mix) twice daily. After two-week feeding, only the concentrate mix was offered for one week in order to induce rapid rumen acidosis. The rumen fluid was collected from each animals twice (on week 2 and week 3 ) at $2 \mathrm{~h}$ after morning feeding using an oral stomach tube. Each collected rumen fluid was analyzed for $\mathrm{pH}$, volatile fatty acid (VFA), and $\mathrm{NH}_{3}-\mathrm{N}$. In addition, differences in microbial community among ruminant species and between normal and an acidosis condition were assessed using two cultureindependent $16 \mathrm{~S}$ polymerase chain reaction (PCR)-based techniques (terminal restriction fragment length polymorphism and quantitative real-time PCR).

Results: The HC decreased ruminal $\mathrm{pH}$ and altered relative concentrations of ruminal VFA $(\mathrm{p}<0.01)$. Total VFA concentration increased in Holstein cows only $(\mathrm{p}<0.01)$. Terminal restriction fragment length polymorphism and real-time quantitative PCR analysis using cultureindependent 16S PCR-based techniques, revealed rumen bacterial diversity differed by species but not by $\mathrm{HC}(\mathrm{p}<0.01)$; bacterial diversity was higher in Korean native goats than that in Holstein cows. HC changed the relative populations of rumen bacterial species. Specifically, the abundance of Fibrobacter succinogenes was decreased while Lactobacillus spp. and Megasphaera elsdenii were increased $(\mathrm{p}<0.01)$.

Conclusion: The HC altered the relative populations, but not diversity, of the ruminal bacterial community, which differed by ruminant species.

Keywords: High Concentrate Diet; Korean Domestic Ruminants; Fermentation Characteristics; Bacterial Diversity; Relative Population

\section{INTRODUCTION}

Ruminants obtain energy and essential nutrients through a complicated symbiotic relationship with the rumen microbiome. The rumen bacterial community is affected by the type of feed ingested by the host ruminants [1]. Changes in the bacterial community in the rumen can significantly affect the health and productivity of host ruminants [2]. In order to improve the productivity of livestock ruminants, a high forage diet is commonly switched to a high concentrate diet (HC), which alters the rumen ecosystem. A HC increases the number of lactic acid producers, such as Streptococcus bovis (S. bovis) and Lactobacillus spp., due to its high level of non-structural carbohydrates (NSC) [3]. A HC also increases the number of lactic acid utilizers, for example, Megasphaera elsdenii (M. elsdenii), Selenomonas ruminantium 
(S. ruminantium), Veillonella parvula [3], it drastically decreases the number of fiber-degrading bacteria such as Fibrobacter succinogenes (F. succinogenes) and Ruminococcus spp. mainly due to a reduction in $\mathrm{pH}$ [2]. Due to the rapid fermentation of NSC, volatile fatty acid (VFA) and lactic acid accumulate in the rumen, causing the $\mathrm{pH}$ to decrease [4]. If the $\mathrm{pH}$ decreases below 5.6, acid-resistant bacteria such as Lactobacillus spp. become dominant in the rumen and this environment is disrupted [3]. In this state of lactic acidosis, the host ruminant may experience intake depression, reduced fiber digestion, milk fat depression, diarrhea, ruminitis, lameness, liver abscesses, inflammation, pneumonia, and even death [5]. To prevent or abate the negative effects of increasing the level of concentrates in the diet, a better understanding of the dynamics of the rumen bacterial community is critical.

Numerous studies have reported that the rumen bacterial community is affected by various factors such as species, diet, age, health condition, feed additives, season, and geographical location $[2,6]$. Several studies have been conducted to characterize the rumen bacterial community in ruminants (e.g., dairy cattle, beef cattle, buffalo, sheep, and goat) fed a HC [7-10]. However, comparative studies on differences among species related to dietary change are scarce, especially for domestic ruminants in Korea. There is one study by Lee et al [11] that compared the rumen microbial communities of three Korean domestic ruminant species, Hanwoo steers (Bos taurus coreanae), Holstein-Friesian dairy cattle, and Korean native goats (Capra hircus coreanae). Experimental conditions (e.g., diet and management), however, were not controlled in their experiment. In addition, individual variation within each species was not considered.

Therefore, the objective of this study was to investigate the differences in rumen fermentation characteristics and changes in microbial communities associated with the sudden introduction of a $\mathrm{HC}$ in three ruminant species. The three ruminants selected for this study were Hanwoo cows, Holstein cows, and Korean native goats. Rumen fermentation characteristics (i.e., $\mathrm{pH}, \mathrm{NH}_{3}-\mathrm{N}$, and VFAs) were determined and two cultureindependent techniques, terminal restriction fragment length polymorphism (T-RFLP) and real-time quantitative polymerase chain reaction (PCR), were used to analyze the diversity of rumen microbial communities.

\section{MATERIALS AND METHODS}

\section{Animal care}

This study was conducted at the Center for Animal Science Research, Chungnam National University, Korea. The protocols for this experiment were reviewed and approved by the Chungnam National University Animal Research Ethics Committee (CNU-00455).

\section{Animals and diets}

Four non-pregnant, non-lactating Hanwoo cows $(546 \pm 33.6$ $\mathrm{kg}$ ), four non-pregnant, non-lactating Holstein cows (516 \pm 42.7 $\mathrm{kg}$ ), and four Korean native goats $(19 \pm 1.4 \mathrm{~kg})$, individually housed, were used in this 3-week experiment. All animals were fed the same diet composed of timothy hay and a commercial concentrate mix (CM). The chemical compositions of the timothy hay and CM are presented in Table 1. The diet was fed ad libitum twice daily at 0800 and 1800 . During the first two weeks, a mixed ration with $800 \mathrm{~g} / \mathrm{kg}$ timothy hay and $200 \mathrm{~g} / \mathrm{kg}$ CM was offered. On the following week, only the CM was fed to the animals to induce acidosis-like conditions in the rumen. Drinking water was freely accessible by animals throughout the experimental period.

\section{Collection and preparation of rumen fluid}

Rumen fluid was sampled twice (after the 2-week period of

Table 1. Chemical composition (g/kg DM or as stated) of the ruminant diet

\begin{tabular}{lcc}
\hline Item & Timothy hay & Concentrate mix $^{1)}$ \\
\hline DM (g/kg as fed) & 887 & 864 \\
OM & 924 & 938 \\
CP & 75 & 149 \\
SOLP & 25 & 48 \\
NDICP & 13 & 22 \\
ADICP & 12 & 15 \\
aNDF & 657 & 245 \\
ADF & 450 & 124 \\
ADL & 68 & 33 \\
Ether extract & 14 & 40 \\
Ash & 76 & 62 \\
TDN & 535 & 766 \\
NEm (MJ/kg DM) & 5.0 & 7.6 \\
NEg (MJ/kg DM) & 2.6 & 5.0 \\
Total carbohydrates & 835 & 750 \\
NFC & 191 & 526 \\
Carbohydrate fractions (g/kg carbohydrate) & \\
CA & 117 & 115 \\
CB1 & 9 & 536 \\
CB2 & 103 & 51 \\
CB3 & 574 & 194 \\
CC & 196 & 104 \\
\hline DM & &
\end{tabular}

$D M$, dry matter; OM, organic matter; $C P$, crude protein; SOLP, soluble CP; NDICP, neutral detergent insoluble $C P$; $A D I C P$, acid detergent insoluble $C P$; aNDF, neutral detergent fiber analyzed using a heat stable amylase and expressed inclusive of residual ash; $A D F$, acid detergent fiber; $A D L$, acid detergent lignin; TDN, total digestible nutrients; NEm, net energy for maintenance; NEg, net energy for growth; NFC, non-fiber carbohydrate; $\mathrm{CA}$, carbohydrate $\mathrm{A}$ fraction, ethanol soluble carbohydrates; $\mathrm{CB} 1$, carbohydrate $B 1$ fraction of starch; $C B 2$, carbohydrate $B 2$ fraction of soluble fiber; CB3, carbohydrate $\mathrm{B} 3$ fraction of available insoluble fiber; $\mathrm{CC}$, carbohydrate $\mathrm{C}$ fraction of unavailable carbohydrate.

1) Concentrate mix (g/kg DM): 249 corn flakes, 186 ground corn, 96 ground wheat, 35 rice bran, 69 gluten feed, 43 wheat flour, 18 dried distillers grains with solubles, 84 palm kernel meal, 60 copra meal, 49 cottonseed hulls, 45 molasses, 11 palm olein oil, 24 limestone, 6 salt, 3 magnesium oxide (50\%), 1 sodium bicarbonate, 5 ammonium chloride, 13 CMS/MSG, 2 rapeseed meal, 1 vitamin and mineral mix. 
high forage feeding on day 14 and after the 1-week period of high concentrate feeding on day 21). Samples were collected using an oral stomach tube $2 \mathrm{~h}$ after each morning feeding as described by Duffield et al [12]. Briefly, after initially obtained rumen fluid (approximately $200 \mathrm{~mL}$ ) was discarded, $500 \mathrm{~mL}$ of rumen fluid was collected in a glass flask. The $\mathrm{pH}$ of the rumen fluid was analyzed immediately after its collection using a general purpose $\mathrm{pH}$ meter (EcoMet P25, Istek, Inc., Seoul, Korea), and then the rumen fluid was transferred to the laboratory. Fifty milliliters of rumen fluid was stored at $-20^{\circ} \mathrm{C}$ until DNA was extracted. Ten milliliters of the rumen fluid was centrifuged at $14,000 \times g$ for $10 \mathrm{~min}$ at $4^{\circ} \mathrm{C}$, and two $1-\mathrm{mL}$ aliquots of the supernatants were each transferred to a 2-mL Eppendorf tube and stored at $-20^{\circ} \mathrm{C}$ until VFAs and $\mathrm{NH}_{3}-\mathrm{N}$ concentrations were analyzed.

\section{Analysis of rumen fermentation characteristics}

The VFA concentration was determined as described by Erwin et al [13]. Briefly, $1 \mathrm{~mL}$ of rumen fluid supernatant was mixed with $0.2 \mathrm{~mL}$ of metaphosphoric acid $(250 \mathrm{~g} / \mathrm{L})$ and held at $4^{\circ} \mathrm{C}$ for $30 \mathrm{~min}$. After re-centrifugation of the mixture at $14,000 \times \mathrm{g}$ for $10 \mathrm{~min}$ at room temperature, the supernatant was injected into a gas chromatograph (HP 6890, Hewlett-Packard CO., Palo Alto, CA, USA) equipped with a flame ionization detector and capillary column (Nukol fused silica capillary column $30 \mathrm{~m} \times 0.25 \mathrm{~mm} \times 0.25 \mu \mathrm{m}$, Supelco, Inc., Bellefonte, PA, USA). The temperature of the oven, injector, and detector were $90^{\circ} \mathrm{C}$ to $180^{\circ} \mathrm{C}, 185^{\circ} \mathrm{C}$, and $210^{\circ} \mathrm{C}$, respectively. Nitrogen was used as the carrier gas at a flow rate of $40 \mathrm{~mL} / \mathrm{min}$. The $\mathrm{NH}_{3}-\mathrm{N}$ concentration was analyzed by the method of Chaney and Marbach [14]. After re-centrifuging the stored rumen fluid at 20,000 $\times \mathrm{g}$ for $15 \mathrm{~min}, 20 \mu \mathrm{L}$ of the supernatant was mixed with $1 \mathrm{~mL}$ of phenol color reagent and $1 \mathrm{~mL}$ of alkali-hypochlorite reagent. The mixture was then incubated in a $37^{\circ} \mathrm{C}$ water bath for 15 $\mathrm{min}$. After the incubation, $8 \mathrm{~mL}$ of distilled water was added to the mixture and the $\mathrm{NH}_{3}-\mathrm{N}$ concentration was determined by measuring the absorbance at $630 \mathrm{~nm}$ with a spectrophotometer (UV-1800, Shimadzu Inc., Kyoto, Japan).

\section{DNA extraction}

The DNA was extracted from each rumen fluid sample as described by Rius et al [15]. Each $25 \mathrm{mg}$ of homogenized and freeze-dried rumen fluid was added to a bead beating vial with screw cap containing a $0.7-\mathrm{g}$ baked $0.1 \mathrm{~mm}$ diameter zirconia/silica bead, $200 \mu \mathrm{L}$ of $20 \%$ sodium dodecyl sulfate solution $282 \mu \mathrm{L}$ buffer A ( $\mathrm{NaCl} 0.2 \mathrm{M}$, Tris $0.2 \mathrm{M}$, ethylenediaminetetraacetic acid $0.02 \mathrm{M}$; pH 8.0), $268 \mu \mathrm{L}$ buffer PM (QIAquick 96 PCR Purification Kit, Qiagen Inc., Valencia, CA, USA), $550 \mu \mathrm{L}$ phenol/chloroform/isoamyl alcohol mixture (25:24:1, vol:vol:vol; $\mathrm{pH} 8.0$ ) and bead beating for $4 \mathrm{~min}$ at full speed using a Mini-Beadbeater-96 (BioSpec Products Inc., Bartlesville, OK, USA). After centrifugation $(20,000 \times g$ for 20 $\min$ at $\left.4^{\circ} \mathrm{C}\right), 500 \mu \mathrm{L}$ of supernatant was transferred into a 1.5-mL microcentrifuge tube, mixed with $650 \mu \mathrm{L}$ of buffer PM (Qiagen, USA), and then applied to a column (QIAquick 96 PCR Purification Kit, USA) to bind the extracted DNA. After washing bound DNA with $700 \mu \mathrm{L}$ of buffer PE (Qiagen, USA), the DNA was eluted into $1.5-\mathrm{mL}$ microcentrifuge tubes using $50 \mu \mathrm{L}$ of elution buffer $(10 \mathrm{mM}$ Tris, $\mathrm{pH} 8.5$ with $\mathrm{HCl})$.

\section{Terminal restriction fragment length polymorphism analysis}

To determine differences in microbial composition among rumen samples, a T-RFLP analysis was performed on the amplified 16S rRNA fragment of the DNA extracted from rumen fluid as described by Fernando et al [7]. Using $100 \mathrm{ng}$ of extracted DNA, the 16S rRNA gene was PCR amplified using Takara Ex Taq (Takara Bio Inc., Shiga, Japan) and a Takara PCR Thermal Cycler Dice Gradient (Takara Bio Inc., Japan). The primers used were a 6-carboxyfluorescein (6-FAM)-labeled forward primer (primer FAMBacT0008F, 5'-AGAGTTT GATCCTGGCTCAG-3') and an unlabeled reverse primer (primer BacT0805R, 5'-GGACTACCAGGGTATCTAATCCC $\left.-3^{\prime}\right)$. The $50-\mu \mathrm{L}$ PCR mixture contained $2 \mu \mathrm{L}$ of DNA (100 ng), $0.25 \mu \mathrm{L}$ of Takara Ex Taq polymerase, $5 \mu \mathrm{L}$ of $10 \times$ Ex Taq buffer, $4 \mu \mathrm{L}$ of deoxynucleoside triphosphate (dNTP) mixture $(2.5 \mathrm{mM}), 2 \mu \mathrm{L}$ each of forward and reverse primers, and 35 $\mu \mathrm{L}$ of sterile distilled water. The cycling conditions were 1 cycle of $1 \mathrm{~min}$ at $95^{\circ} \mathrm{C}, 30 \mathrm{~s}$ at $52^{\circ} \mathrm{C}$, and $1 \mathrm{~min}$ at $72^{\circ} \mathrm{C}$, followed by 34 cycles of $30 \mathrm{~s}$ at $95^{\circ} \mathrm{C}, 30 \mathrm{~s}$ at $52^{\circ} \mathrm{C}$, and $1 \mathrm{~min}$ at $72^{\circ} \mathrm{C}$, and a final extension step of $3 \mathrm{~min}$ at $72^{\circ} \mathrm{C}$. The PCR amplicon was digested by the restriction enzymes HaeIII (Takara Bio Inc., Japan), MspI, and RsaI (Enzynomics, Daejeon, Korea), and then sequenced using a BigDye Terminator v3.1 Cycle Sequencing Kit (Applied Biosystems Inc., Foster City, CA, USA) and ABI 3730XL DNA Analyzer (Applied Biosystems Inc., USA). During the T-RFLP experiment, one of the samples of a Hanwoo cow was damaged; therefore, we were only able to obtain data from three Hanwoo cows.

The T-RFLP data (size, base pair, and peak area for each T-RF) were analyzed as described by Abdo et al [16]. All TRFLP electropherograms were visually inspected, and the size and peak heights were tabulated using Peak Scanner Software (Applied Biosystems Inc., USA). T-RFs less than $27 \mathrm{bp}$ and greater than $520 \mathrm{bp}$ were discarded. True peaks were identified based on peak heights. Briefly, the standard deviation of the heights of total peaks was calculated assuming that the true mean of the background equaled zero. Peaks that had heights greater than three standard deviations were identified and defined as true peaks. After removing the true peaks from the dataset, the identification process was repeated until no peaks with heights greater than three standard deviations were present in the dataset.

The sizes of the fragments in a sample were determined also 
by the method proposed by Abdo et al [16]. Data were binned after pooling all fragment lengths of true peaks. After sorting the fragment lengths, duplicate lengths in multiple samples were identified and eliminated. These duplicated fragment lengths were then binned and represented by their average length. Peak heights of binned fragments from the same sample were summed. For each sample, peak heights were standardized by dividing peak heights of fragments in a bin by the sum of peak heights within the sample. The standardized peak heights thus represented the relative abundance of each fragment. The pooled T-RFLP peak heights were used to calculate the Shannon index and the inverse Simpson index as estimates of the diversity of microbial communities in each sample using an R package, Vegan.

\section{Real-time polymerase chain reaction}

Relative quantification of the ruminal bacteria from each rumen fluid sample was performed using quantitative real-time PCR (qPCR) with primers targeting the 16S rRNA gene of different rumen microbial species (Table 2). Real-time PCR amplification was performed on a Bio-Rad CFX 96 Connect Real-Time PCR Detection System (Bio-Rad Laboratories Inc., Hercules, CA, USA), and data were analyzed using Bio-Rad CFX Manager software (version 3.0). Reactions were performed in triplicate in a total volume of $20 \mu \mathrm{L}$ in 96-well Hard-Shell PCR plates (Bio-Rad, USA) sealed with PCR film (PCR Sealers Microseal 'B', Bio-Rad Laboratories Inc., USA). The reaction mixture (per well) contained $10 \mu \mathrm{L}$ of SYBR Green Real-Time PCR Master Mix (Toyobo Co., Ltd., Osaka, Japan), $1 \mu \mathrm{L}$ each of forward and reverse primers, $2 \mu \mathrm{L}$ of DNA template from a rumen fluid sample, and $6 \mu \mathrm{L}$ of PCR grade water. The PCR cycling conditions were an initial denaturation step at $95^{\circ} \mathrm{C}$ for $1 \mathrm{~min}$, followed by 40 cycles of denaturation at $95^{\circ} \mathrm{C}$ for
$15 \mathrm{~s}$, annealing at $60^{\circ} \mathrm{C}$ for $15 \mathrm{~s}$, and extension at $72^{\circ} \mathrm{C}$ for $45 \mathrm{~s}$. Finally, a melting curve analysis was performed by slowly cooling the reaction mixture from $95^{\circ} \mathrm{C}$ to $65^{\circ} \mathrm{C}$ to detect nonspecific amplification products. All reactions were performed in triplicate. The abundance of each target bacteria was calculated relative to the total rumen bacteria population according to the equation $2^{-\Delta \mathrm{Ct}}=2^{-(\mathrm{Ct} \text { target-Ct total bacteria) }}$, as described by Denman and McSweeney [17]. The relative abundance of bacteria was expressed as a percentage of total rumen bacteria $\left(100 \times 2^{-\Delta C t}\right)$.

\section{Statistical analysis}

Data for rumen parameters and the relative quantities of rumen microbial species were analyzed using the MIXED procedure in SAS version 9.4 (SAS Institute Inc., Cary, NC, USA). Animal, nested within species, was included in the model as a random variable. Degrees of freedom were adjusted using KENWARDROGER. A variance component was used in the variance-covariance matrix. The linear model used for the analysis was as follows:

$$
y_{i j k l}=\mu+\tau_{i}+b_{j(i)}+\rho_{k}+(\tau \rho)_{i k}+e_{i j k l}
$$

Where: $y_{i j k l}$ is the kth observation in the ith ruminant species and jth diet, $\mu$ is the overall mean, $\tau_{i}$ is the fixed effect of the ith species ( $\mathrm{i}=1$ to 3 ), $b_{j(i)}$ is the random effect of the $\mathrm{jth}$ animal within the ith species, $\rho_{k}$ is the fixed effect of the kth $\operatorname{diet}(\mathrm{i}=1$ to 2$),\left(\tau_{\rho}\right)_{i k}$ is the interaction between species and diet, and $e_{i j k l}$ is the unexplained random error.

Differences among means were also compared by Tukey's test when there was a significant overall effect. Statistical significance was set at $\mathrm{p}<0.05$, and $0.05 \leq \mathrm{p}<0.1$ was considered a trend.

Table 2. Primer sets used for relative quantification of bacterial species in the rumen using real-time polymerase chain reaction

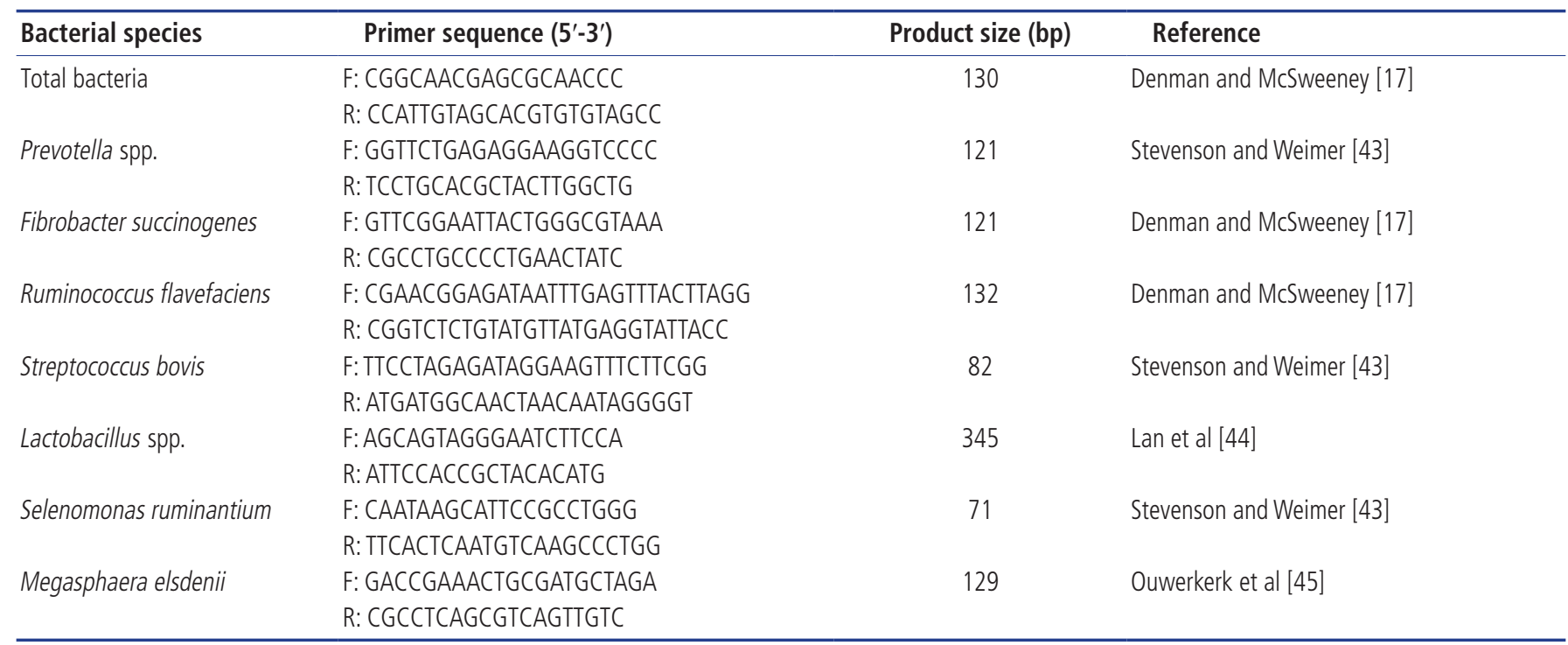


A complete-linkage hierarchical cluster analysis (HCA) was performed on the T-RFLP profiles using the hclust function in R version 3.0.2 (http://www.r-project.org/). Euclidean distances were used to generate a distance matrix. A dendrogram of clusters was generated using an R package, dendextend. A principal component analysis (PCA) was also performed without any further normalization to reduce the dimensionality of explanatory variables (i.e., fragment lengths) using the prcomp function in R. PCA results extracted from T-RFLP profiles were plotted with the first principal component on the $\mathrm{x}$-axis and the second principal component on the y-axis.

\section{RESULTS}

\section{Rumen fermentation characteristics}

A rumen acidosis-like condition was achieved in each of the Korean domestic ruminant species by providing only CM (Table 3). The mean ruminal $\mathrm{pH}$ decreased, on average, from 6.34 to 5.53 within one week of introducing this $\operatorname{diet}(\mathrm{p}<0.01)$. The extent of this reduction, however, differed by species $(\mathrm{p}<$ 0.01 ). The decrease in $\mathrm{pH}$ units was 1.23 in Holstein cows, while it was only 0.3 in goats. The ruminal $\mathrm{NH}_{3}-\mathrm{N}$ concentration showed a tendency to increase 1.92 -fold, on average, after the introduction of the HC ( $\mathrm{p}=0.096)$.

A significant interaction between species and diet was apparent in the VFA concentrations $(\mathrm{p}<0.01)$. A greater increase in total VFA concentration with the change in diet was observed in Holstein cows ( 63.15 to $121.62 \mathrm{mM}, 1.93$-fold) than in the other two species. With the diet change, the proportion of acetate significantly decreased, while that of butyrate and valerate significantly increased in all species $(p<0.01)$. The acetate to propionate $(\mathrm{A} / \mathrm{P})$ ratio significantly decreased with the diet change overall $(\mathrm{p}<0.01)$, but significant differences between species were also observed $(\mathrm{p}=0.049)$. The $\mathrm{A} / \mathrm{P}$ ratio remained the same in goats (2.6 vs 2.6 ), despite the shift to a HC. This was related with no change in the proportion of propionate in goats although it was increased in the other species, which leaded to a tendency toward an interaction between species and diet $(\mathrm{p}=0.066)$. A significant interaction between species and diet was observed in the proportion of branchchained VFAs (i.e., isobutyrate and isovalerate). The molar proportion of branch-chained VFAs decreased with the diet change in Holstein cows, but it remained the same in Hanwoo cows and even tended to increase in goats $(\mathrm{p}<0.05)$.

\section{Diversity in rumen microbial communities}

There were significant differences between species in the diversity of rumen microbial communities $(p=0.022)$; however, the change to a $\mathrm{HC}$ did not affect microbial diversity in the rumen (Table 4). Higher microbial diversity was observed in Korean native goats compared with the two cattle species, based on the Shannon diversity index and Inverse-Simpson index. The diversity indices were significantly lower in Holstein cows than that in goats $(\mathrm{p}<0.05)$.

An HCA of the T-RFLP data was performed to assess a relative homogeneity in rumen bacterial community structures among the different animal species and diets (Figure 1). Although no systematic patterns were observed in the clusters, there was a tendency toward more similar microbial communities among goats and among Hanwoo cows when they were fed a HC. PCA indicated that diet was more important in determining the bacterial community structure than species (Figure 2). The first principal component (PC1) explained 21\% of the data variance, and the second principal component (PC2) explained $16 \%$ of the data variance.

Relative population of selected bacterial species

Relative populations of selected bacterial species in the rumen

Table 3. Rumen fermentation characteristics in Korean domestic ruminants fed a high forage (HF) vs a high concentrate diet (HC)

\begin{tabular}{|c|c|c|c|c|c|c|c|c|c|c|}
\hline \multirow{2}{*}{ Variables } & \multicolumn{2}{|c|}{ Hanwoo } & \multicolumn{2}{|c|}{ Holstein } & \multicolumn{2}{|c|}{ Goat } & \multirow{2}{*}{ SEM } & \multicolumn{3}{|c|}{ p-value } \\
\hline & $H F^{1)}$ & $\mathrm{HC}^{2)}$ & HF & $\mathrm{HC}$ & HF & $\mathrm{HC}$ & & Species & Diet & Species xdiet \\
\hline $\mathrm{pH}$ & $6.39^{a}$ & $5.56^{b c}$ & $6.37^{\mathrm{a}}$ & $5.14^{c}$ & $6.25^{\mathrm{a}}$ & $5.90^{\mathrm{ab}}$ & 0.121 & 0.119 & $<0.01$ & $<0.01$ \\
\hline $\mathrm{NH}_{3}-\mathrm{N},(\mathrm{mg} / \mathrm{dL})$ & 1.27 & 4.97 & 2.56 & 4.84 & 5.19 & 7.51 & 1.890 & 0.264 & 0.096 & 0.908 \\
\hline Total VFA (mM) & $74.3^{b}$ & $81.5^{b}$ & $63.1^{b}$ & $121.6^{a}$ & $59.4^{b}$ & $53.8^{b}$ & 6.81 & $<0.01$ & $<0.01$ & $<0.01$ \\
\hline \multicolumn{11}{|l|}{ VFA (mmol/mol) } \\
\hline Acetate & $590^{\mathrm{a}}$ & $470^{b}$ & $585^{a}$ & $464^{b}$ & $562^{a}$ & $478^{b}$ & 13.2 & 0.779 & $<0.01$ & 0.310 \\
\hline Propionate & 175 & 272 & 170 & 210 & 218 & 198 & 23.4 & 0.383 & 0.054 & 0.066 \\
\hline Butyrate & $123^{b}$ & $130^{a b}$ & $118^{b}$ & $215^{a}$ & $88^{b}$ & $164^{\mathrm{ab}}$ & 18.1 & 0.093 & $<0.01$ & 0.071 \\
\hline Isobutyrate & $59^{a b}$ & $55^{\mathrm{ab}}$ & $68^{a b}$ & $38^{b}$ & $71^{\mathrm{a}}$ & $82^{\mathrm{a}}$ & 6.3 & 0.011 & 0.145 & 0.026 \\
\hline Valerate & $28^{c}$ & $46^{a b}$ & $31^{b c}$ & $55^{\mathrm{a}}$ & $34^{b c}$ & $44^{a b c}$ & 4.2 & 0.480 & $<0.01$ & 0.199 \\
\hline Isovalerate & $25^{a b}$ & $28^{a b}$ & $29^{\mathrm{ab}}$ & $18^{a b}$ & $27^{a b}$ & $35^{\mathrm{a}}$ & 3.3 & 0.105 & 0.954 & 0.024 \\
\hline A:P ratio & $3.4^{\mathrm{a}}$ & $1.8^{b}$ & $3.5^{\mathrm{a}}$ & $2.5^{\mathrm{ab}}$ & $2.6^{a b}$ & $2.5^{\mathrm{ab}}$ & 0.29 & 0.316 & $<0.01$ & 0.049 \\
\hline
\end{tabular}

SEM, standard error of the mean; VFA, volatile fatty acid.

1) HF, high forage diet; TMR with $800 \mathrm{~g} / \mathrm{kg}$ timothy hay and $200 \mathrm{~g} / \mathrm{kg}$ concentrate mix.

${ }^{2)} \mathrm{HC}$, high concentrate diet; only the concentrate mix.

${ }^{a-c}$ Means that do not have common superscripts significantly differ within the species $(p<0.05)$. 
Table 4. Diversity of the microbial communities in rumens of Korean domestic ruminants fed a high forage (HF) vs a high concentrate diet (HC) using terminal restriction fragment length polymorphism data

\begin{tabular}{|c|c|c|c|c|c|c|c|c|c|c|}
\hline \multirow{2}{*}{ Index } & \multicolumn{5}{|c|}{ Species $^{1)}$} & \multicolumn{4}{|c|}{$\operatorname{Diet}^{2)}$} & \multirow{2}{*}{$\begin{array}{c}\text { Species } \times \text { diet } \\
p \text {-value }\end{array}$} \\
\hline & Hanwoo & Holstein & Goat & SEM & $p$-value & HF & $\mathrm{HC}$ & SEM & $p$-value & \\
\hline Shannon index & $2.73^{\mathrm{ab}}$ & $2.56^{\mathrm{b}}$ & $2.92^{\mathrm{a}}$ & 0.100 & 0.022 & 2.72 & 2.76 & 0.075 & 0.691 & 0.407 \\
\hline Inverse-simpson index & $11.78^{\mathrm{ab}}$ & $9.74^{b}$ & $14.67^{\mathrm{a}}$ & 1.292 & 0.022 & 11.44 & 12.69 & 0.963 & 0.373 & 0.632 \\
\hline
\end{tabular}

SEM, standard error of the mean.

1) Hanwoo, Korean native cow; Holstein, Holstein cow; Goat, Korean native goat.

2) $\mathrm{HF}$, high forage diet, TMR with $800 \mathrm{~g} / \mathrm{kg}$ timothy hay and $200 \mathrm{~g} / \mathrm{kg}$ concentrate mix; HC, high concentrate diet, only the concentrate mix.

$a, b$ Means that do not have common superscripts significantly differ within the species $(p<0.05)$.

fluid of Korean domestic ruminants were also analyzed using real-time quantitative PCR (Table 5). The relative abundance of Prevotella spp. was $42 \%$, on average, and it did not differ by either diet or species.

Among the cellulolytic bacterial species, the relative abundance of F. succinogenes, but not Ruminococcus flavefaciens ( $R$. flavefaciens), significantly decreased with high concentrate feeding $(\mathrm{p}<0.01)$. A greater reduction in the proportion of $F$. succinogenes was observed in Korean native goats than in the other animal species (13-fold; $\mathrm{p}<0.01)$.
Among major species of lactate producers in the rumen, Lactobacillus spp. significantly increased (39-fold; $\mathrm{p}<0.05$ ), whereas $S$. bovis did not change significantly with the switch to a HC ( $p>0.1)$. S. ruminantium, known as both a lactic acid producer and utilizer, did not show a significant change with the diet transition ( $p>0.1)$. A great increase (approximately 1,700 -fold) in the relative proportion of M. elsdenii, a major lactate utilizer, was observed $(\mathrm{p}<0.01)$ in all experimental animal species fed a HC.

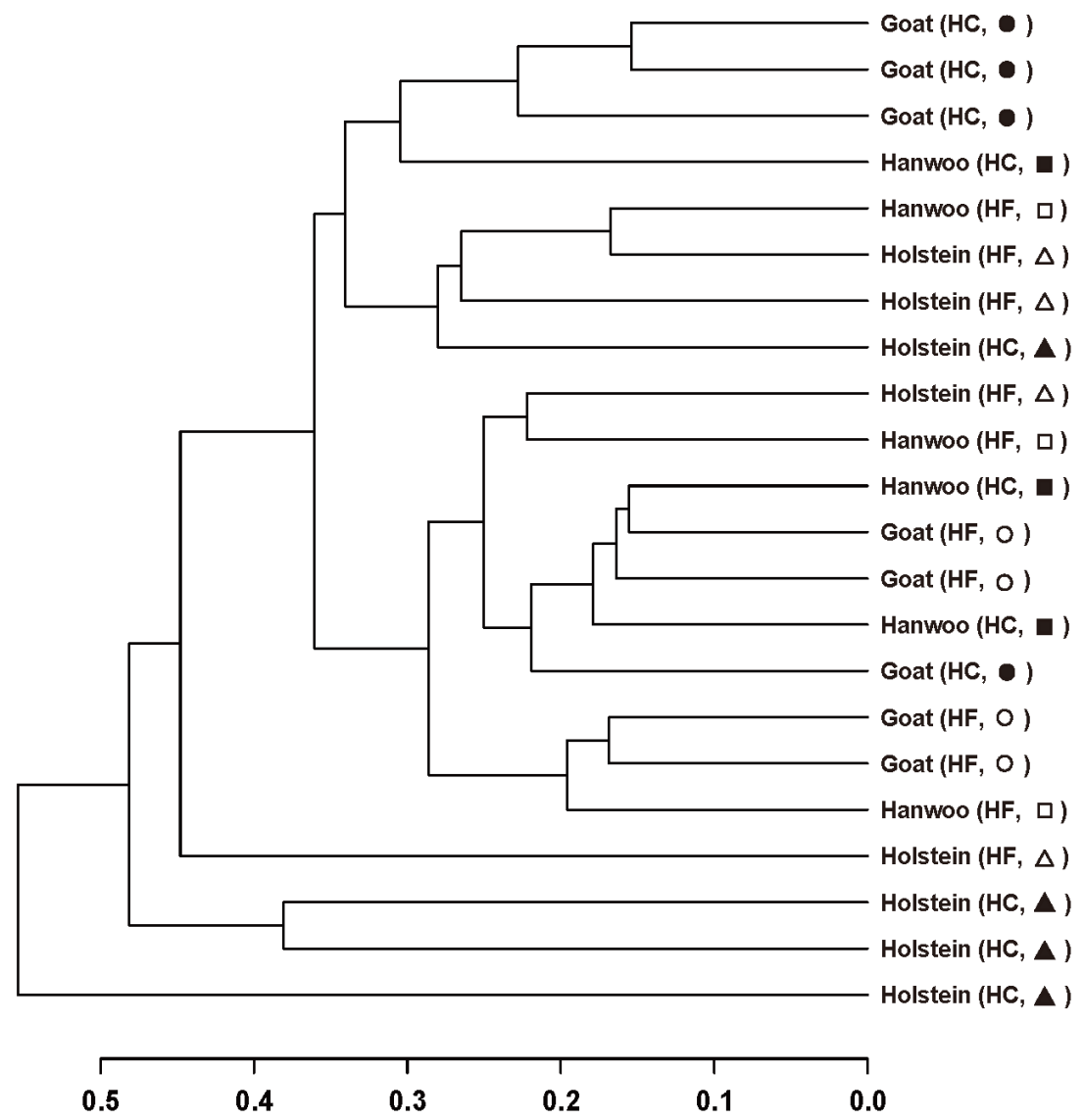

Figure 1. Hierarchical cluster analysis of the similarity of microbial communities in the rumens of Korean domestic ruminants fed a high forage (HF) vs a high concentrate diet $(\mathrm{HC})$ using terminal restriction fragment length polymorphism data. A dendrogram generated by calculating the Euclidean distance between normalized peak heights. Symbols are as follows: Hanwoos fed a high forge $(H F, \square)$ or a high concentrate $(H C, \mathbf{\square})$ diet; Holsteins fed a high forage $(H F, \Delta)$ or a high concentrate $(H C, \mathbf{\Delta})$ diet; goats fed a high forage $(\mathrm{HF}, \mathrm{o})$ or a high concentrate $(\mathrm{HC}, \bullet)$ diet. 
Table 5. Relative abundance (\% of total bacteria) of selected bacterial species in the rumens of Korean domestic ruminants fed a high forage (HF) vs a high concentrate (HC) diet

\begin{tabular}{|c|c|c|c|c|c|c|c|c|c|c|}
\hline \multirow{2}{*}{ Bacterial species } & \multicolumn{2}{|c|}{ Hanwoo } & \multicolumn{2}{|c|}{ Holstein } & \multicolumn{2}{|c|}{ Goat } & \multirow{2}{*}{ SEM } & \multicolumn{3}{|c|}{$p$-value } \\
\hline & $\mathrm{HF}^{1)}$ & $\mathrm{HC}^{2)}$ & HF & $\mathrm{HC}$ & $\mathrm{HF}$ & $\mathrm{HC}$ & & Species & Diet & Species $\times$ diet \\
\hline Prevotella spp. & 37.921 & 40.747 & 41.885 & 37.905 & 39.599 & 51.827 & 3.7177 & 0.193 & 0.240 & 0.120 \\
\hline F. succinogenes & $0.774^{\mathrm{ab}}$ & $0.039^{b}$ & $0.819^{\mathrm{ab}}$ & $0.099^{b}$ & $2.187^{\mathrm{a}}$ & $0.171^{b}$ & 0.3642 & 0.087 & $<0.01$ & 0.153 \\
\hline R. flavefaciens & 0.010 & 0.025 & 0.016 & 0.001 & 0.008 & 0.003 & 0.0081 & 0.296 & 0.801 & 0.186 \\
\hline S. bovis & 2.715 & 0.020 & 0.782 & 0.011 & 0.158 & 0.015 & 0.9344 & 0.380 & 0.132 & 0.383 \\
\hline Lactobacillus spp. & 0.016 & 0.380 & 0.040 & 1.041 & 0.002 & 0.862 & 0.3862 & 0.680 & 0.041 & 0.691 \\
\hline S. ruminantium & 3.475 & 3.037 & 3.632 & 3.169 & 5.812 & 3.902 & 1.4698 & 0.497 & 0.445 & 0.850 \\
\hline M. elsdenii & $0.001^{b}$ & $1.450^{\mathrm{ab}}$ & $0.002^{b}$ & $3.402^{\mathrm{a}}$ & $0.001^{b}$ & $1.692^{\mathrm{ab}}$ & 0.7372 & 0.373 & $<0.01$ & 0.374 \\
\hline
\end{tabular}

SEM, standard error of the mean.

1) HF, high forage diet, TMR with $800 \mathrm{~g} / \mathrm{kg}$ timothy hay and $200 \mathrm{~g} / \mathrm{kg}$ concentrate mix.

2) $\mathrm{HC}$, high concentrate diet, only the concentrate mix.

$a, b$ Means that do not have common superscripts significantly differ within the species $(p<0.05)$.

\section{DISCUSSION}

All ruminants interact closely with rumen microorganisms. The rumen microbes supply VFAs, proteins, and vitamins to the host ruminant by degrading and fermenting feed materials [1]. The ruminal bacterial community composition can change depending on the type of diet ingested by the ruminant animal [1]. Studies on microbial communities and ruminal characteristics are important for understanding and manipulating the health and performance of ruminant animals. Previous studies have shown that changes in rumen microbial communities are affected by factors such as ruminant species, diet, age, health, feed additives, season, and geographical location $[2,6,18,19]$. In particular, a diet switch from high forage to high concentrate can cause a large change in the rumen bacterial community, which can affect productivity and the potential for metabolic disease in ruminants [20]. In general, a HC increases the number of both lactic acid producers and utilizers and, while the number of fiber-degrading bacteria drastically decrease because of the low fiber content and reduction in $\mathrm{pH}$ resulting from the accumulation of lactic acid in the rumen [10]. Because of changes in the bacterial community, total VFA and lactic acid concentrations in the rumen increase [4]. When the $\mathrm{pH}$ decreases below 5.6, Lactobacillus spp., more acid-re-

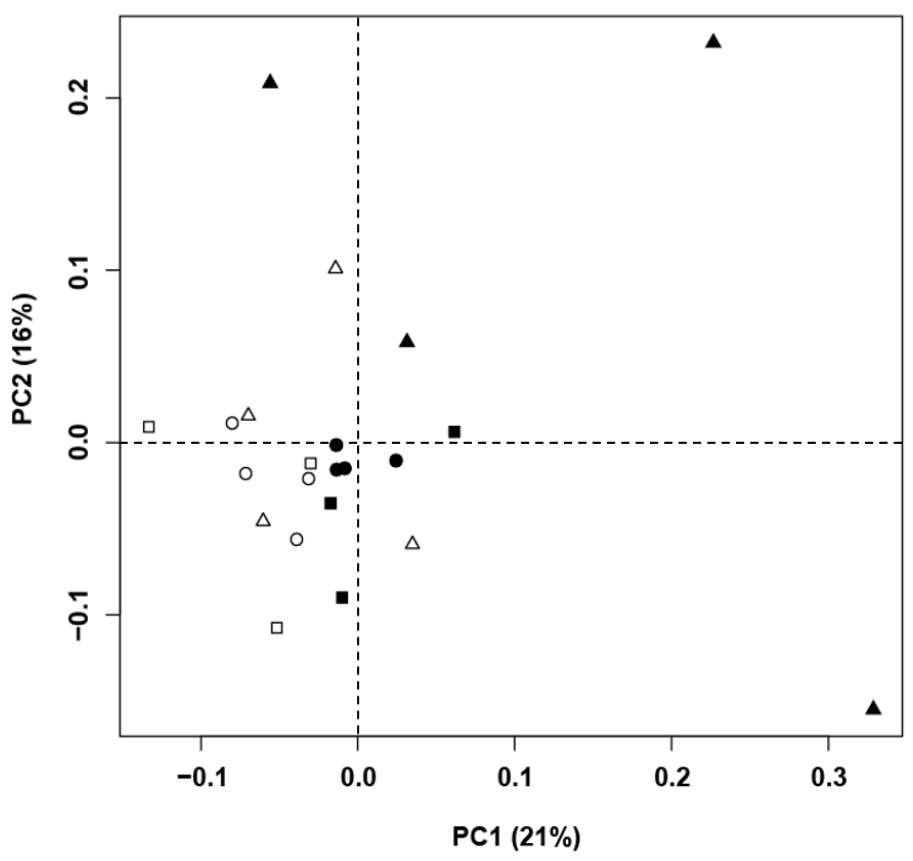

Figure 2. Principal component analysis of the similarity of microbial communities in the rumens of Korean domestic ruminants fed a high forage (HF) vs a high concentrate diet (HC) using terminal restriction fragment length polymorphism data. The first principal component (PC1, $x$-axis) explained $21 \%$ and the second principal component (PC2, y-axis) explained $16 \%$ of the total variance. Symbols are as follows: Hanwoos fed a high forge (HF, $\square)$ or a high concentrate (HC, $\mathbf{\square})$ diet; Holsteins fed a high forage $(H F, \Delta)$ or a high concentrate $(H C, \boldsymbol{\Delta})$ diet; goats fed a high forage $(H F, o)$ or a high concentrate $(H C, \bullet)$ diet. 
sistant than other microbes, become dominant in the rumen, which can cause metabolic disorders [4]. Despite the fact that it is important to understand the changes in the rumen microbial communities resulting from supplying a $\mathrm{HC}$, little research has been done on the microbial communities of ruminant species in Korea. In the present study, changes in the rumen condition and microbial communities by supplying a $\mathrm{HC}$ were investigated in three ruminant species (Hanwoo, a major beef breed; Holstein, a major dairy breed; Korean native goat) commonly raised in the intensive farming system in Korea. They were housed in similar conditions and fed the same diet.

Based on the proposed $\mathrm{pH}$ thresholds to define the ruminal acidosis when rumen fluid samples are collected by using an oral stomach tube [12,21], it seemed that Hanwoo cows were experienced a subacute ruminal acidosis. Also, Holstein cows seem to had an acute ruminal acidosis-like condition because the $\mathrm{pH}$ of rumen fluid below 5.2 unit is considered to be the development of acute ruminal acidosis [22]. According to the those threshold, Korean native goats also showed subacute ruminal acidosis condition, however, the $\mathrm{pH}$ change of Korean native goats were no significant after introduction of $\mathrm{HC}$ compared to the cattle species. It seemed that Holstein cows were more susceptible while Korean native goats more resistant to ruminal acidosis. After providing only the $\mathrm{CM}$, there were a dramatic increase in total VFA concentration and a significant reduction in $\mathrm{pH}$ in Holstein cows. In the goats, however, no such changes were observed. A reduction in ruminal $\mathrm{pH}$ is closely related with the concentration of total VFAs. Previous studies showed an increase in the concentration of VFA rather than lactate primarily affected the ruminal $\mathrm{pH}$ in response to high concentrate feeding in cattle [23]. In our study, an increase in total VFAs was observed in both cattle species. Changes in relative proportions of individual VFAs followed a typical response to an acidosis-like condition in the rumen $[4,24]$. However, total VFA concentration of Korean native goats did not increase with the feed change and thus the ruminal $\mathrm{pH}$ was little reduced. A week of feeding a $\mathrm{HC}$ may not be sufficient to induce ruminal acidosis in Korean native goats. Previous studies have indicated Korean native goats may be resistant to reduction in ruminal $\mathrm{pH}$ by dietary changes. Even feeding a HC ( $800 \mathrm{~g} / \mathrm{kg} \mathrm{CM}$ and $200 \mathrm{~g} / \mathrm{kg}$ forage) for 21 days was not able to reduce the ruminal $\mathrm{pH}$ of Korean native goats less than 6.0 [25]. Although Lee et al [11] could induce acidosis like condition $(\mathrm{pH}<5.11)$ in Korean native goats by feeding a diet composed of $900 \mathrm{~g} / \mathrm{kg} \mathrm{CM}$ and $100 \mathrm{~g} / \mathrm{kg}$ forage, they did not report the duration of feeding the diet.

Early studies on the rumen ecosystem used culture-based methods to identify microorganisms $[1,26]$. However, due to the fastidious growth requirements of many rumen microbes, culture-based methods have important limitations for the assessment of microbial changes, namely, they substantially underestimate microbial diversity in the rumen and fail to detect major microbes. Therefore, studies on changes in microbial diversity in the rumen now use molecular techniques. Whitford et al [27] was the first to analyze the phylogenetic diversity of rumen microbial communities based on 16s rRNA sequences, and to demonstrate that many microbes present in the rumen were difficult to culture. Tajima et al [20] reported a rumen bacterial transition with a change from roughage to a high-grain diet in Holstein cows, based on a 16S rRNA sequence analysis. Since then, a variety of molecular analytical methods have been developed and used to evaluate this microbial transition. T-RFLP analysis, denaturing gradient gel electrophoresis (PCR-DGGE), real-time PCR, and pyrosequencing methods have been widely used in recent studies on dairy cattle, beef cattle, sheep, and goats [7-10].

In our study, we determined changes in the structure and diversity of bacterial communities in the rumen using T-RFLP analysis, as well as changes in specific bacterial species using real-time PCR analysis. The Shannon index and Inverse-Simpson Index calculated based on the results from a T-RFLP analysis indicated diversity of bacterial community in the rumen were more diverse in goats compared with Holstein cows. This is the first study that directly compared the diversity of bacterial community between Korean native goats and Holstein cows, and further study is warranted to decipher the differences in the microbial communities between two species. In addition, the diversity of bacterial community was not altered by a HC, which was consistent with previous studies $[8,28,29]$. It may indicate that feeding a $\mathrm{HC}$ for a week did not change the diversity but the structure of bacterial community in the rumen.

The changes in the structure of bacterial community in the rumen by feeding a $\mathrm{HC}$ were supported by the results from HCA and PCA analyses. HCA and PCA showed a tendency of clustering of ruminal bacterial communities more by diet than species, and suggest that rumen bacterial community structure was influenced by the HC. Comparative analysis using a real-time PCR clearly showed changes in the structure of bacterial community in the rumen by feeding a HC. Realtime PCR analysis is a powerful method that can be used to quantify specific target DNA sequences [30]. We confirmed significant changes in the relative populations of $F$. succinogenes, Lactobacillus spp., and M. elsdenii among the seven major bacterial species.

A 12-fold decrease, on average, in the proportion of $F$ succinogenes in all animals was observed in this study. F. succinogenes is one of the dominant cellulolytic bacteria species in rumen [31]. A reduction of $F$. succinogenes following the switch from a high forage diet to $\mathrm{HC}$ was also noted in some previous reports. Tajima et al [10] showed that the proportion of $F$. succinogenes decreased 20 -fold on day 3 and decreased 57 -fold on day 28 in animals after a change to a HC. A 40-fold reduction in this population with the introduction of a $\mathrm{HC}$ was also reported by Fernando et al [7]. On the other hand, there was 
no significant change in the $R$. flavefaciens population in the present study, which was consistent with a previous study [32]. The reason for this is unclear, but $R$. flavefaciens showed high resistance to low rumen $\mathrm{pH}$ than $F$. succinogenes.

As agreed with previous studies, the proportion of Lactobacillus spp. was drastically increased after feeding a HC. On the contrary, there was a reduction in the population of $S$. bovis with persistent acidity in the rumen, which was consistent with other studies [7,10,33]. S. bovis and Lactobacillus spp. are known as typical lactic acid-producing bacteria, and they are primarily responsible for reducing the $\mathrm{pH}$ in the rumen [34]. Generally, the ruminal population of $S$. bovis is increased when animals were fed a diet composed of a highly fermentable carbohydrate source such as glucose or starch. However, as the ruminal $\mathrm{pH}$ becomes more acidic $(<6.0)$, its growth diminished, and Lactobacillus spp., more tolerant to low $\mathrm{pH}$ than $\mathrm{S}$. bovis, becomes dominant in the acidic rumen when $\mathrm{pH}$ is less than 5.6 [35].

With the accumulation of lactic acid in the rumen resulting from a $\mathrm{HC}$, the numbers of bacteria that utilize lactic acid increase [36]. M. elsdenii and S. ruminantium are the predominant lactic acid utilizers in the rumens of animals fed a HC [36,37]. M. elsdenii uses $60 \%$ to $80 \%$ lactic acid in the rumen; therefore, M. elsdenii helps prevent accumulation of lactic acid in the rumen [38]. In this study, the M. elsdenii proportion drastically increased relative to other major bacteria with the change to a HC. Fernando et al [7] also reported an increase in the M. elsdenii proportion, based on a real-time PCR analysis. While the proportion of $S$. ruminantium did not change significantly in this study, some studies have reported otherwise. Tajima et al [10] reported an approximately 9-fold increase in this species in animals fed a HC. Similarly, Fernando et al [7] reported a 30-fold increase the S. ruminantium proportion. However, some recent studies showed similar results to our current study which were report that there was no significant change in population of $S$. ruminantium when ruminal acidosis was induced $[39,40]$. There have been reports that $S$. ruminantium grows slowly in acidic rumen [41] and is less able to use lactic acid than $M$. elsdenii, because its lactic dehydrogenase is repressed by glucose and maltose [42]. These results may support findings in the current study.

In summary, based on the results from the analyses of rumen fermentation characteristics and rumen bacterial community structure, differences between the three animal species fed a HC were apparent. Based on rumen fermentation characteristics, both cattle species showed signs of acidosis. In particular, Holstein cows showed greater sensitivity to the concentrate diet than the other two native Korean species, exhibiting signs of severe acidic (acute acidosis-like) conditions. Further, we were able to confirm that there is a change in the rumen bacterial community structure, and that the most significant change occurred in the Holstein cow. Results of the real-time PCR analysis of the major bacteria associated with acidosis showed a reduction in cellulolytic bacteria and an increase in lactic acid producers and utilizers. Unlike the structure of bacterial community, the bacterial diversity was not affected by feeding a $\mathrm{HC}$ for a week. The diversity of bacterial community, however, significantly differed by ruminant species. To determine why acidosis does not progress in the rumens of native Korean goats and to precisely determine the degree of rumen acidosis within each ruminant species, continuous monitoring of $\mathrm{pH}$ and lactate concentrations in rumen beginning with the introduction of a $\mathrm{HC}$ will be needed. Because of the considerable variability between animals within the same species, the number of experimental animals in each species should be increased. Despite the differences in rumen fermentation characteristics and rumen bacterial community structure observed between animal species, the real-time PCR analysis result could not refine these differences. Therefore, to better identify the changes in bacterial populations in an acidified rumen, the classification level of target bacteria should be expanded from species to genus and family.

\section{CONFLICT OF INTEREST}

We certify that there is no conflict of interest with any financial organization regarding the material discussed in the manuscript.

\section{ACKNOWLEDGMENTS}

This research was supported by the Bioindustry Technology Development Program (Project No. 312030-04-4-HD060), Ministry of Agriculture, Food and Rural Affairs, Republic of Korea.

\section{REFERENCES}

1. Hungate RE. The rumen and its microbes. New York, USA: Academic Press; 1966.

2. Russell JB. Rumen microbiology and its role in ruminant nutrition. Ithaca, NY, USA: J.B. Russell Publishing Co.; 2002.

3. Mackie R, Gilchrist FM. Changes in lactate-producing and lactate-utilizing bacteria in relation to $\mathrm{pH}$ in the rumen of sheep during stepwise adaptation to a high-concentrate diet. Appl Environ Microbiol 1979;38:422-30.

4. Goad DW, Goad CL, Nagaraja TG. Ruminal microbial and fermentative changes associated with experimentally induced subacute acidosis in steers. J Anim Sci 1998;76:234-41.

5. Lean IJ, Wade LK, Curtis MA, Porter J. New approaches to control of ruminal acidosis in dairy cattle. Asian-Australas J Anim 2000;13(Suppl):266-9.

6. Henderson G, Cox F, Ganesh S, et al. Rumen microbial community composition varies with diet and host, but a core microbiome is found across a wide geographical range. Sci Rep 
2015;5:14567.

7. Fernando SC, Purvis H, Najar F, et al. Rumen microbial population dynamics during adaptation to a high-grain diet. Appl Environ Microbiol 2010;76:7482-90.

8. Huo W, Zhu W, Mao S. Impact of subacute ruminal acidosis on the diversity of liquid and solid-associated bacteria in the rumen of goats. World J Microbiol Biotechnol 2014;30:669-80.

9. Lettat A, Nozière P, Silberberg M, et al. Rumen microbial and fermentation characteristics are affected differently by bacterial probiotic supplementation during induced lactic and subacute acidosis in sheep. BMC Microbiol 2012;12:142.

10. Tajima K, Aminov RI, Nagamine T, et al. Diet-dependent shifts in the bacterial population of the rumen revealed with realtime PCR. Appl Environ Microbiol 2001;67:2766-74.

11. Lee HJ, Jung JY, Oh YK, et al. Comparative survey of rumen microbial communities and metabolites across one caprine and three bovine groups, using bar-coded pyrosequencing and $1 \mathrm{H}$ nuclear magnetic resonance spectroscopy. Appl Environ Microbiol 2012;78:5983-93.

12. Duffield T, Plaizier JC, Fairfield A, et al. Comparison of techniques for measurement of rumen $\mathrm{pH}$ in lactating dairy cows. J Dairy Sci 2004;87:59-66.

13. Erwin E, Marco G, Emery E. Volatile fatty acid analyses of blood and rumen fluid by gas chromatography. J Dairy Sci 1961;44: 1768-71.

14. Chaney AL, Marbach EP. Modified reagents for determination of urea and ammonia. Clin Chem 1962;8:130-2.

15. Rius AG, Kittelmann S, Macdonald KA, et al. Nitrogen metabolism and rumen microbial enumeration in lactating cows with divergent residual feed intake fed high-digestibility pasture. J Dairy Sci 2012;95:5024-34.

16. Abdo Z, Schüette UM, Bent SJ, et al. Statistical methods for characterizing diversity of microbial communities by analysis of terminal restriction fragment length polymorphisms of $16 \mathrm{~S}$ rRNA genes. Environ Microbiol 2006;8:929-38.

17.Denman SE, McSweeney CS. Development of a real-time PCR assay for monitoring anaerobic fungal and cellulolytic bacterial populations within the rumen. FEMS Microbiol Ecol 2006;58: 572-82.

18. Nie Y, Zhou Z, Guan J, et al. Dynamic changes of yak (Bos grunniens) gut microbiota during growth revealed by polymerase chain reaction-denaturing gradient gel electrophoresis and metagenomics. Asian-Australas J Anim Sci 2017;30:957-66.

19.Zhan J, Liu M, Wu C, et al. Effects of alfalfa flavonoids extract on the microbial flora of dairy cow rumen. Asian-Australas J Anim Sci 2017;30:1261-9.

20. Tajima K, Arai S, Ogata K, et al. Rumen bacterial community transition during adaptation to high-grain diet. Anaerobe 2000;6:273-84.

21. Plaizier JC. Replacing chopped alfalfa hay with alfalfa silage in barley grain and alfalfa-based total mixed rations for lactating dairy cows. J Dairy Sci 2004;87:2495-505.
22. Owens FN, Secrist DS, Hill WJ, Gill DR. Acidosis in cattle: a review. J Anim Sci 1998;76:275-86.

23. Burrin D, Britton R. Response to monensin in cattle during subacute acidosis. J Anim Sci 1986;63:888-93.

24. Khafipour E, Li S, Plaizier JC, Krause DO. Rumen microbiome composition determined using two nutritional models of subacute ruminal acidosis. Appl Environ Microbiol 2009;75: 7115-24.

25.In SH, Shin HT, Baig SY, Chung KH. Effects of lasalocid supplementation on the ruminal fermentation and digestibility of Korean native goats. J Anim Sci Technol 2001;43:101-10.

26. Bryant MP. Bacterial species of the rumen. Bacteriol Rev 1959; 23:125-53.

27. Whitford MF, Forster RJ, Beard CE, Gong J, Teather RM. Phylogenetic analysis of rumen bacteria by comparative sequence analysis of cloned 16S rRNA genes ß. Anaerobe 1998;4:153-63.

28. Ye H, Liu J, Feng P, Zhu W, Mao S. Grain-rich diets altered the colonic fermentation and mucosa-associated bacterial communities and induced mucosal injuries in goats. Sci Rep 2016;6: 20329.

29. Liu K, Xu Q, Wang L, et al. The impact of diet on the composition and relative abundance of rumen microbes in goat. AsianAustralas J Anim Sci 2017;30:531-7.

30.Freeman WM, Walker SJ, Vrana KE. Quantitative RT-PCR: pitfalls and potential. BioTechniques 1999;26:112-25.

31. Koike S, Kobayashi Y. Development and use of competitive PCR assays for the rumen cellulolytic bacteria: Fibrobacter succinogenes, Ruminococcus albus and Ruminococcus flavefaciens. FEMS Microbiol Lett 2001;204:361-6.

32. Chiquette J, Allison M, Rasmussen M. Use of Prevotella bryantii $25 \mathrm{~A}$ and a commercial probiotic during subacute acidosis challenge in midlactation dairy cows. J Dairy Sci 2012;95:598595.

33. Petri RM, Schwaiger T, Penner GB, et al. Characterization of the core rumen microbiome in cattle during transition from forage to concentrate as well as during and after an acidotic challenge. PloS ONE 2013;8: e83424.

34. Allison MJ, Robinson IM, Dougherty RW, Bucklin JA. Grain overload in cattle and sheep: changes in microbial populations in the cecum and rumen. Am J Vet Res 1975;36:181-5.

35. Nagaraja TG, Titgemeyer EC. Ruminal acidosis in beef cattle: the current microbiological and nutritional outlook. J Dairy Sci 2007;90:E17-38.

36. Huber TL, Cooley JH, Goetsch DD, Das NK. Lactic acid-utilizing bacteria in ruminal fluid of a steer adapted from hay feeding to a high-grain ration. Am J Vet Res 1976;37:611-3.

37. Mackie RI, Gilchrist F, Robberts AM, Hannah PE, Schwartz HM. Microbiological and chemical changes in the rumen during the stepwise adaptation of sheep to high concentrate diets. J Agric Sci 1978;90:241-54.

38. Counotte GHM, Prins RA. Regulation of lactate metabolism in the rumen. Vet Res Commun 1981;5:101-15. 
39. Malekkhahi M, Tahmasbi AM, Naserian AA, et al. Effects of supplementation of active dried yeast and malate during subacute ruminal acidosis on rumen fermentation, microbial population, selected blood metabolites, and milk production in dairy cows. Anim Feed Sci Technol 2016;213:29-43.

40. McCann JC, Luan S, Cardoso FC, et al. Induction of subacute ruminal acidosis affects the ruminal microbiome and epithelium. Front Microbiol 2016;7:701.

41.Therion JJ, Kistner A, Kornelius JH. Effect of $\mathrm{pH}$ on growth rates of rumen amylolytic and lactilytic bacteria. Appl Environ Microbiol 1982;44:428-34.

42. Russell JB, Baldwin RL. Substrate preferences in rumen bacteria: evidence of catabolite regulatory mechanisms. Appl
Environ Microbiol 1978;36:319-29.

43. Stevenson DM, Weimer PJ. Dominance of Prevotella and low abundance of classical ruminal bacterial species in the bovine rumen revealed by relative quantification real-time PCR. Appl Microbiol Biotechnol 2007;75:165-74.

44.Lan Y, Xun S, Tamminga S, et al. Real-time PCR detection of lactic acid bacteria in cecal contents of eimeria tenella-lnfected broilers fed soybean oligosaccharides and soluble soybean polysaccharides. Poult Sci 2004;83:1696-702.

45. Ouwerkerk D, Klieve AV, Forster RJ. Enumeration of Megasphaera elsdenii in rumen contents by real-time Taq nuclease assay. J Appl Microbiol 2002;92:753-8. 